\title{
Saúde: Direito ou Privilégio?
}

Health: Right or Privilege?

Salud: ¿Derecho o Privilégio?

Aline Cristina de Andrade Alves Zufelatto ${ }^{1}$

Renato Periard Alves ${ }^{2}$

RESUMO: O presente artigo apresenta uma reflexão crítica acerca da saúde como direito de todos e privilégio de alguns, considerando aspectos legais, sociais e políticos onde se verifica a importância do conceito da saúde e o respeito aos preceitos legais aplicáveis visando garantir sua promoção à população de forma igualitária e efetiva.

Palavras-chave: Direito à Saúde. Políticas Públicas. Responsabilidade Social.

ABSTRACT: This article presents a critical reflection on health as a right of all and privilege of some, considering legal, social and political aspects where the importance of the concept of health is verified and the respect to the applicable legal precepts in order to guarantee its promotion to the population of form egalitarian and effective.

Keywords: Right to Health, Public Policies. Social Responsibility.

RESUMEN: El presente artículo presenta una reflexión crítica sobre la salud como derecho de todos y privilegio de algunos, considerando aspectos legales, sociales y políticos donde se verifica la importancia del concepto de la salud y el respeto a los preceptos legales aplicables para garantizar su promoción a la población de forma igualitaria y efectiva.

Palabras-Ilave: Derecho a la Salud, Políticas Públicas. Responsabilidad Social.

\footnotetext{
${ }^{1}$ Bacharel em Direito pela Universidade Veiga de Almeida, Especialista em Direito Sanitário pela Escola Nacional de Saúde Pública Sérgio Arouca. Analista de Gestão em Saúde. E-mail: alinecaazuf@gmail.com ${ }^{2}$ Médico veterinário pelo Centro Universitário de Barra Mansa - RJ, Especialista em Direito Sanitário pela Escola Nacional de Saúde Pública Sérgio Arouca. Chefe da Divisão de Tecnologia e Inspeção da Secretaria Municipal de Agricultura do Município de Piraí/RJ. E-mail: renatoperiard@hotmail.com
} 


\section{Introdução}

O Direito à saúde integra um conjunto dos direitos chamados sociais, aqueles que se inspiram no escopo da igualdade entre os indivíduos. No Brasil este direito apenas foi reconhecido na Constituição Federal de 1988, antes disso o Estado oferecia atendimento à saúde para trabalhadores com carteira assinada e suas famílias, os demais cidadãos obtinham acesso a estes serviços como um favor e não como um direito. Durante a Constituinte de 1988 as responsabilidades do Estado foram reavaliadas e a promoção da saúde de todos passa a ser um de seus deveres:

A saúde é direito de todos e dever do Estado, garantido mediante políticas sociais e econômicas que visem à redução do risco de doença e de outros agravos e ao acesso universal e igualitário às ações e serviços para a promoção, proteção e recuperação (1)

Este dispositivo legal não deve ser visto como uma promessa ou uma declaração de intenções, pois se trata de um direito fundamental do cidadão que tem aplicação imediata, isto é, pode e deve ser garantido.

A saúde é um direito de todos por que sem ela não há condições de uma vida digna, e é um dever do Estado por que é financiada pelos impostos que são pagos pela população. Destarte, a fim de que o direito à saúde seja uma realidade, é necessário que o Estado crie condições de atendimento em postos de saúde, hospitais, programas de prevenção, medicamentos, além de outros elementos além do atendimento ser universal, ou seja, alcançando a todos os que precisam e integral, garantindo tudo o que o cidadão possa precisar.

A criação do Sistema Único de Saúde (SUS) reflete o reconhecimento por parte do Estado na assunção da responsabilidade de assegurar 0 direito ao cidadão. A inspiração do SUS vai além da disponibilização de postos de saúde e hospitais para atender às necessidades da população, a idéia é que seja possível agir preventivamente através dos agentes de saúde visitando as famílias e conhecendo a realidade de cada indivíduo, promovendo o encaminhamento das pessoas para os equipamentos públicos de saúde quando necessário. Assim, efetivamente se cumpre o objetivo de proteger, promover e recuperar a saúde do cidadão brasileiro, detentor de direitos e tutelado pelo Estado, independente da região que vive se produtivos ou não e de quais os seus sintomas. 
Ainda que previsto em lei, este sistema não tem sua eficácia completamente consolidada, as falhas são muitas e ainda há de se trabalhar intensamente para que o serviço público de saúde alcance o nível desejado e merecido pelos brasileiros, o que infelizmente confere a saúde como direito de todos, porém privilégio de poucos.

\section{Do conceito de Saúde}

Preliminarmente, visando à clareza dos argumentos aqui propostos, é de elevada consideração demarcar um conceito de saúde, destacando que esta discussão nunca se deixou calar ao longo dos tempos.

O primeiro conceito de saúde que se tem notícia, provavelmente foi externado pelos pensadores da Grécia Antiga, através do qual já dizia o brocardo Mens Sana In Corpore Sano, considerado um marco da definição de saúde. Todavia, o termo "saúde" se traduz em diversas idéias, eis que ora se relacionava entre o homem e o meio ambiente, outrora como ausência de doenças físicas e mentais.

Foi a partir do Século XX com a implementação da Organização Mundial da Saúde (OMS) no ano de 1946, a saúde foi definida como o "completo bem-estar físico, mental e social e não apenas a ausência de doenças ou outros agravos” (2) destarte, reconhecida como um dos direitos fundamentais de todo ser humano, não importante sua condição social ou econômica e sua crença religiosa ou consciência política.

Desta feita, pode-se dizer que a saúde é uma eterna busca pelo equilíbrio entre corpo, mente, ambiente, vontades e tantos outros elementos influentes no bem-estar humano.

Entretanto, a conceituação de saúde externada pela OMS sofreu muitas críticas, considerando que as verbas públicas podem correr o risco de não serem suficientes para a efetivação de um completo bem-estar físico, mental e social. Assim, preconiza Kraunt (3), acerca do conceito de saúde externado pela OMS, la aplicación de este concepto reconoce límites culturales, sociales y económicos.(4)

Não obstante, o conceito de saúde é, também, uma questão de o cidadão ter direito a uma vida saudável, digna, com autonomia para fazer o que tiver vontade com qualidade, podendo, sempre que quiser ou precisar, lançar mão do desenvolvimento 
tecnológico, respeitando o próximo e o meio ambiente, é claro, tudo isso objetivando livrar o ser humano de seus males e garantir seu bem-estar.

\section{A Saúde é sim um direito}

Ao se definir saúde, é natural conceber a afirmativa de que a saúde correlacionada com o direito constitui um direito social, isto é, o direito à saúde presente em vários artigos da Carta Constitucional de 1988, como: arts. $5^{\circ}, 6 \stackrel{\circ}{7} 7^{\circ}, 21,22,23,24,30,127$, 129, 133, 134, 170, 182, 184, 194, 195, 197, 198, 199, 200, 216, 218, 220, 225, 227 e 230. Partindo deste pressuposto, o direito à saúde constitui uma obrigação do Estado, enquanto guardião da população, a agir positivamente visando garantir e proteger a saúde.

Nota-se que a mais nobre doutrina jurídica moderna em sua respeitável interpretação da lei, bem como, nos próprios textos legais atuais, que o direito à saúde interage com vários outros direitos, como exemplo: direito ao saneamento, direito à moradia, direito à educação, direito ao bem-estar social, direito à seguridade social, direito à assistência social, direito de acesso aos serviços médicos e direito à saúde física e mental.

É incontestável a relação da saúde com a educação, por exemplo, já que a informação e o conhecimento agem no sentido de prevenção dos males que alcançam o homem. Pode-se afirmar, também, que a saúde é correlata com o trabalho, uma vez que este representa porção fundamental na vida dos seres humanos e por derradeiro é pressuposto para o cidadão desempenhar bem as suas atividades, bem como a sua segurança no que diz respeito a doenças e acidentes advindos do trabalho.

Ressalte-se que os direitos sociais se encontram no Capítulo II do Título II da Carta Constitucional de 1988. O Título II da Constituição alinha os direitos e garantias fundamentais. Neste contexto, é correto dizer que estando os direitos sociais delineados em um capítulo situado e regido pelos direitos e garantias fundamentais, resta concluir que os direitos sociais (como a saúde) são direitos fundamentais do Ser Humano e que possuem os mesmos atributos e garantia destes direitos.

Ainda que dúvida houvesse, bem como qualquer fragilidade de entendimento, a Lei

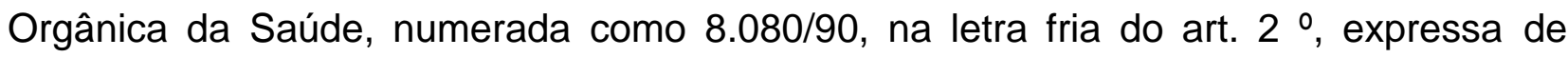


forma clara quanto à natureza dos direitos sociais, ao preceituar que "a saúde é um direito fundamental do ser humano, devendo o Estado prover de condições indispensáveis ao seu pleno exercício" (5)

\section{A obrigação do Estado}

A Constituição Federal de 1988, em seu artigo 196 preceitua claramente que a saúde é um direito de todos e dever do Estado. Sendo assim, a obrigação do Estado é pressuposto basilar na promoção e proteção à saúde, considerando que se vive em um Estado Democrático de Direito $^{3}$.

Sendo a saúde um dever do Estado, este tem a obrigação de determinar as ações e serviços públicos de saúde, já que para efetivação e concretização da saúde, o art. 198 da CF/88 estabelece que estas ações e serviços públicos concernentes à saúde, sejam designados, através de uma ação integrada, em um sistema único, de forma regionalizada e hierarquizada. Este sistema único é realizado através da Lei no 8.080/90, que estabelece o SUS - Sistema Único de Saúde. Destarte, a Administração Pública está diretamente ligada à promoção e efetivação do direito à saúde. Eis que o art. 4 da Lei 8.080/90 é inequívoco ao estabelecer que as ações e serviços de saúde serão prestados por todas as instituições públicas federais, estaduais e municipais do Poder Público, que da mesma forma constituem o SUS.

É importante ressaltar quanto ao outro aspecto inerente ao dever do Estado no que concerne à saúde: a sua gratuidade. O Estado é obrigado a promover a saúde para os cidadãos de forma gratuita, haja vista que ao investir recursos públicos no sistema de saúde, não objetiva explorar economicamente tal atividade, sim prestar um serviço público adequado ao direito fundamental da dignidade do homem.

Sendo assim, o direito à saúde é de fato um direito originário a prestações, tendo em vista a sua característica de direito público subjetivo efetivando prestações materiais visando à proteção da qualidade de vida. Desta feita, é decorrente diretamente da

\footnotetext{
3 Por Estado Democrático de Direito, entende-se a superação das desigualdades sociais e também regionais e instaurar um regime democrático que se efetive a justiça social, está diretamente ligada à qualidade de vida. Isto posto, é oportuno afirmar que a saúde é pressuposto da qualidade de vida, desejada por todo cidadão.
} 
Constituição, consubstanciando em uma exigência inderrogável de qualquer Estado que exprima nos seus pilares valorações básicas, a dignidade humana e à justiça social.

Para a efetivação do direito à saúde, é mister que o Estado designe uma sistemática para tal, e, isto posto, esta efetivação dar-se-á mediante políticas sociais e econômicas.

Isto posto, o direito à saúde é um direito fundamental social e para que a saúde realmente faça parte da qualidade de vida do cidadão e da dignidade humana, é necessário que o Estado atue positivamente.

As políticas sociais e econômicas, devem também viabilizar um acesso igualitário e universal para qualquer ser humano, independente de raça, credo, cor, religião etc. Assim, todo e qualquer cidadão, inclusive o estrangeiro tem o direito à saúde, direito de ser atendido pelo Sistema Único de Saúde, justamente por ser um cidadão com direitos fundamentais inerentes a sua pessoa. (4)

Por derradeiro, o dever do Estado para com a saúde, é de agir no sentido de garantir às pessoas o direito à saúde, e diante disto, o Estado também possui imposição constitucional de promover a saúde, não apenas curando e prevenindo doenças, como também alterando o sistema social, por meio de uma construção mutante, que melhora cada vez mais a qualidade de vida, claramente expressa nos direitos alinhados no art. 3 o da Lei $\mathrm{n}$ 8.080/90.

Ressalte-se que não é só a promoção, acesso igualitário e universal, e redução de doenças e outros agravos que delineiam o papel das políticas sociais e econômicas como obrigação do Estado na efetivação do direito à saúde. Pois a proteção e a recuperação da saúde como políticas sociais e econômicas são de total relevância nessa questão.

Vale atentar que a defesa da saúde, é dever do Estado em todas as suas esferas de poder político, pois as ações e serviços para efetivação da saúde são de relevância pública. Já a competência para o direito sanitário, na sua efetivação, é do Estado como um todo, haja vista que a Constituição vigente não isentou qualquer esfera do dever de promover, proteger, defender e cuidar da saúde. A responsabilidade é da União, dos Estados, do Distrito Federal e dos Municípios. 
Não obstante, o art. 197 da Constituição de 1988, não exclui a participação de terceiros e também, pessoas físicas ou jurídicas de direito privado na execução de ações e serviços para com a saúde.

Desta forma, as políticas sociais e econômicas, garantidas mediante ações e serviços de saúde, de acordo com o art. 198 da CF/88, serão através de uma rede hierarquizada e regionalizada, constituindo um sistema único, conforme "os princípios de integralidade, igualdade e participação comunitária, que são vinculativos tanto aos serviços executados diretamente pela Administração Pública, como aqueles efetuados através de contratações, convênios, terceiros e particulares" (6).

As políticas sociais e econômicas visam à organização do sistema único de saúde, fazendo com que o mesmo seja acessível e igualitário, através de uma sistemática de interligação de princípios, diretrizes e normas.

O art. 16 da Lei Orgânica da Saúde, aduz expressamente as competências para implementação de políticas, descentralizando as ações e serviços para as Unidades Federadas e para os Municípios.

\section{UPAs - uma alternativa}

Diante da máxima de que a promoção, defesa e proteção da saúde é dever estatal, dentre as ações propostas atualmente visando essas garantias, as Unidades de Pronto Atendimento (UPAS) trazem inovações, bem como calorosas divergências em torno de suas sistemáticas de funcionamento.

Segundo o tenente-coronel do Corpo de Bombeiros e coordenador das UPAs cariocas, Ricardo Bruno (7)

a ideia é atender à demanda de pacientes de urgência, média e baixa complexidade que vão para os hospitais públicos e não conseguem atendimento ou acabam atrapalhando a própria rotina dos hospitais, que têm como função inicial atender grandes emergências.

Embora o serviço de pronto-atendimento encaminhe pacientes graves aos hospitais da rede pública, funcione em horário integral, e ainda possuam consultórios de várias especialidades médicas, salas de sutura, laboratórios, farmácias, entre outros serviços, há quem considere frágil seu poder resolutivo. 
Na corrente contrária (UPA, Não), o Doutor em Saúde Pública pela USP, Dr. Paulo de Tarso Puccini (8) evoca:

\begin{abstract}
Há uma questão primeira sobre as razões que justificam esse tipo de unidade. O questionável é se o tipo de unidade denominado prontoatendimento, organizado para prestar serviço específico para demandas "simples", que adota como forma de trabalho médico o contato pontual, de baixa qualificação profissional e baixa resolubilidade, seria um serviço capaz de pronto-atender de forma integral e qualificada. É forçoso perguntar por que não resolver essas demandas no âmbito do trabalho da unidade básica de saúde ou do pronto-socorro, com seus conjuntos de definições e exigências técnicas e profissionais.
\end{abstract}

O fato é que a população já enxerga a UPA como resolução ainda que a oferta de serviços não acompanhe a demanda, no Estado do Rio de Janeiro já se contam 21 unidades, e há previsão de se implementar mais 29 até 2010, com capacidade para 12 mil atendimentos mensais cada.

O cidadão ao sofrer de qualquer mal, seja por doença ou acidente, deseja um atendimento digno e eficaz, independente do papel de cada serviço público de saúde, a ele não importa se a UPA faz a via da unidade básica ou do grande hospital, as discussões alimentadas até aqui podem corroborar no aparecimento de novas políticas e ações no sentido de elevar a qualidade do atendimento nos serviços públicos de saúde. No entanto, há de se considerar os efeitos do advento das UPAs, visto que muitas vidas têm sido salvas ao passo que a espera por socorro nos grandes hospitais continua asfixiante e em muitos casos, fatal.

Contudo, nascer ou morrer numa fila de hospital reflete uma triste realidade nas unidades públicas de saúde, a falta de profissionais, medicamentos, equipamentos e até leitos há muito denota a fragilidade do sistema, ao ponto de se considerar que o direito à saúde abraça uma parte, pequena, da população brasileira, levando ao pensamento de que é direito de todos, porém privilégio de alguns.

\title{
O alto preço do privilégio saúde
}

Ao se mencionar a saúde como privilégio, embora sendo um direito social fundamental, reflete-se a idéia de que atualmente, diante dos problemas enfrentados pela população, a saúde tem seu preço, alto por sinal, todos sem exceção possuem o direito assegurado na Lei Máxima Pátria, entretanto aqueles que podem pagar tem 
maior acesso a um atendimento digno e efetivo, resguardando sua integridade física e mental mediante o pagamento por boleto ou débito em conta bancária.

Reportando a afirmativa legal de que o acesso aos serviços públicos de saúde deve ser universal e igualitário, bem como de que o Estado possui o dever de gratuidade ao oferecer um serviço de saúde, nos deparamos com o mercado da saúde, com planos diferenciados, hospitais com hotelaria luxuosa, tecnologias avançadas e atendimento adequado.

Ao passo que numa unidade pública de saúde, gestantes dão à luz aos seus filhos em corredores, sem nem mesmo uma maca para ampará-las, profissionais passando pelas mesmas sem sequer olhar para elas, uma pequena parcela de mulheres, tem a felicidade de programar seus partos, ser levada numa cadeira de rodas por uma enfermeira amável e sorridente até o leito, um apartamento com todo o conforto e tranquilidade.

Eis a realidade, nada igualitária, nada justa aos humanos, iguais por natureza e segregados socialmente pelo poder aquisitivo, o papel do estado nesse caso não é construir hospitais de luxo, mas, sim não permitir que uma mãe volte para casa de braços vazios após horas de trabalho de parto, numa fila, sem atendimento, como se não fosse cidadã, como não fosse detentora do direito à saúde.

É válida a ressalva de que o atendimento privado também tem suas mazelas, as autorizações para determinados procedimentos nem sempre são concedidas, geralmente devido à modalidade do plano ou seguro e carências, ocorre que, o privilegiado que pode pagar o plano "master" ou "sênior" corre menos risco de ter uma negativa do que aqueles que possuem os seguros de cobertura mais básica.

Neste enfoque, pondera Guilherme Cintra (9), Mestre em Direito, Estado e Constituição pela UnB:

O mercado privado de saúde não parece se importar muito com isso. Se existe demanda, isto é, se as pessoas estão dispostas a pagar pela sua saúde, a oferta surge naturalmente, explicam os economistas. Afinal de contas, vivemos em uma economia capitalista. Todos têm que garantir o seu "ganha pão". O custo dos tratamentos é alto. Equipamentos, remédios, exames, médicos e enfermeiras custam caro. Logo, não é surpreendente que o preço também seja alto. Não é possível agradar (ou atender) a todos. 
Além disso, não são todas as unidades públicas de saúde que oferecem atendimento ineficiente e ou ineficaz, existem serviços públicos de saúde já considerados referências em determinadas especialidades, como exemplo: Instituto de Pesquisa Clínica Evandro Chagas - IPECIFIOCRUZ (doenças infecto-contagiosas e parasitárias), Instituto Fernandes Figueira - IFF\FIOCRUZ (gestação de risco), Hospital Municipal Jesus (Pediatria), Hospital Estadual Rafael de Paula Lima (tratamento para Tuberculose).

Ainda assim, a diferença aumenta quando se trata do cidadão que nada pode pagar e aquele que possui seguro de ampla cobertura, temos sim hospitais públicos referência, entretanto os mesmos não possuem capacidade para tamanha necessidade da população, além disso, a quantidade de especialidades médicas é vasta perante o número de hospitais e postos de saúde públicos.

Valorar economicamente a saúde significa impor a seletividade no acesso, priorizar o lucro em vez do direito, aumentar a exclusão em lugar da equidade, não há de se culpar o mercado e sim cobrar do Estado ações que possibilitem o atendimento digno, igualitário e resolutivo gratuitamente a todos os brasileiros, não importando o poder aquisitivo, nem outro fator social.

\section{Conclusão}

Embora o direito à saúde seja positivamente expresso, ainda há de se engendrar muitos esforços em prol de sua efetiva aplicação, visto que a universalização do acesso e seu poder resolutivo devem ser insistentemente reivindicados e cabe ao cidadão, titular do direito social e fundamental à saúde exigir sua concretização ao Estado, o responsável pela prestação de serviços gratuitos e decentes.

No entanto essa cobrança exige uma postura ativa e enfática, visando à ampliação da rede pública, majoração de serviços universais e gratuitos, já que o mercado e a sociedade, naturalmente, geram exclusões de difícil regulação.

O fato é que definitivamente deve-se considerar inaceitável a saúde tratada como privilégio, pois ela é, sem dúvida o mais imprescindível pressuposto para a garantia dos demais direitos fundamentais, sem saúde não se vive e sem direito não há vida pacífica 
em sociedade. De todos os elementos que concorrem para o bem-estar do homem, a saúde está acima de todos, inclusive do econômico.

\section{Referências}

1. Brasil. Constituição da República Federativa do Brasil de 1988. Brasília: Senado Federal, 2017

2. Organização Mundial da Saúde-OMS, Constituição da OMS de 1946. Disponível em http://www.direitoshumanos.usp.br/index.php/OMS-Organiza\%C3\%A7\%C3\%A3oMundial-da-Sa\%C3\%BAde/constituicao-da-organizacao-mundial-da-saudeomswho.html. [ Acesso em 3.nov.2017]

3.Kraunt, J.A. Los Derechos de los Pacientes. Buenos Aires: Abeledo Perrot, 1997.

4. Hamenhuk, $\mathrm{H}$. O direito à saúde no Brasil e a teoria dos direitos fundamentais. Revista Jus Navigandi, 9 (227), 2004. Disponível em https://jus.com.br/artigos/4839. [Acesso em : 8 nov.2017.]

5.Brasil. Lei Federal 8080 de 19 de setembro de 1990. Dispõe sobre as condições para a promoção, proteção e recuperação da saúde, a organização e o funcionamento dos serviços correspondentes e dá outras providências. Disponível em http://www.planalto.gov.br/ccivil 03/leis/L8080.htm. [ Acesso em 3.nov.2017]

6. Costa, EA. Vigilância Sanitária: proteção e defesa da saúde. São Paulo: Sobravime, 2004

7. Bruno, R. Revista Radis. comunicação em saúde no 83, Julho de 2009.Disponível em http://www2.camara.gov.br/legislacao/publicacoes/constituicao1988.html/ConstituicaoTe xtoAtualizado-EC64.pdf [ Acesso em 8.nov.2017]

8. Puccini, PT. Upa, Não - Entrevista à Revista Radis comunicação em saúde, no 83 de Julho de 2009, página 15. Disponível em http://www2.camara.gov.br/legislacao/publicacoes/constituicao1988.html/ConstituicaoTe xtoAtualizado-EC64.pdf [ Acesso em 8.nov.2017]

9. Cintra, G. Saúde: direito ou mercadoria. In Alexandre B.Costa et al ( orgs) O Direito Achado na Rua. Introdução Crítica ao Direito à Saúde. Brasília: UnB, 2008 